La decisión judicial a partir del derecho probatorio en

el proceso civil nicaragüense vigente

Everto Antonio Álvarez Jiménez 


\section{La decisión judicial} a partir del derecho probatorio en el proceso civil nicaragüiense vigente
Everto Álvarez Jiménez

Docente-Investigador Departamento de Derecho

Fac. de Humanidades y Ciencias Jurídicas UNAN-Managua

ORCID. 0000-0002-0332-8170 e.alvarezjimenez@hotmail.com

(c) (1) (2) (2) Copyright 12017 UNAN-Managua

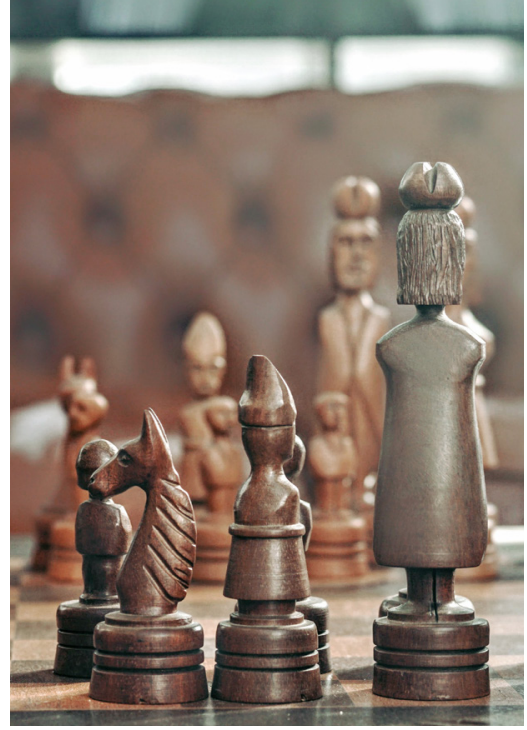

\section{The judicial decision starting from the probative law in the current Nicaraguan civil proceeding}

\section{RESUMEN}

Las ideas que hoy presento intentan examinar uno de los temas muy poco abordados en el entorno profesional. Se trata de aquellas premisas y fases que enrumban la labor judicial de juzgar. En un primer plano, se presenta al lector el sistema por medio del cual se da un valor a cada medio de prueba en nuestro proceso civil actual, para posteriormente abordar las premisas que acercan al judicial a comprobar las afirmaciones de hechos que realizan las partes, y acto seguido se emprende en las fases por las que atraviesa el juez en el amargo camino de interpretar y valorar los resultados probatorios, y motivar su decisión.

\section{ABSTRACT}

The ideas I present through this paper try to examine one of the unusual topic within the professional environment. This is about those premises and phases that move the judicial labor for judging. In the foreground, the system through which it adds value to each means of evidence in our current civil proceeding, it is presented for readers; subsequently, it is addressed the premises that move it closer to the judicial to prove the statements of facts from the parties, and after that, it is set out within the phases the judge faces through the bitter path to interpret and value the probative results, as well as motivate his decision.

\section{PALABRAS CLAVE}

Prueba, derecho probatorio, valoración de la prueba, premisa, fase, sistema de valoración, motivación, sana crítica.

\section{KEY WORDS}

Proof, probative law, assessment of evidence, premise, phase, evaluation system, motivation, reasoned judgment. 
A las reglas legales que disciplinan la prueba le concierne por antonomasia dar respuestas a clásicas interrogantes tales como ¿qué es prueba?, ¿qué se prueba?, ¿con qué se prueba?, ¿quién prueba?, y ¿cómo se valora la prueba? con relación en la Ley No. 902, Código Procesal Civil de Nicaragua (CPCN), en adelante Ley No. 902. En esta ocasión resulta prioritario referirse a dos garantías que ofrece la norma de máxima jerarquía, la Constitución Política (Cn). Por un lado, la Constitución Política consagra el derecho de los justiciables a utilizar todos los medios de prueba pertinentes para garantizar la defensa de sus pretensiones e intereses legítimos (art. 34.4 Cn), y por otro, el deber del judicial de valorar las pruebas propuestas, admitidas y practicadas, como exigencia del deber de motivación de las resoluciones judiciales (art. 34.8 Cn).

No está de más apreciar que existe una estrecha relación entre los hechos sujetos a probanza y la posterior resolución, de modo que nos encontramos ante un binomio de causa-efecto, donde las partes gozan del derecho de utilizar los medios de prueba relevantes para el esclarecimiento de las afirmaciones de hecho y el juez está sometido a motivar su decisión con base en los medios de prueba propuestos, admitidos y practicados.

Dicho lo anterior cabe precisar, si no es ya evidente, que las ideas vertidas en este pequeño escrito son tributarias de la "decisión judicial" y específicamente de aquello que se conoce como las premisas y fases del juicio de veracidad de los resultados probatorios, teniendo en cuenta que la puesta en marcha de la reforma en materia procesal civil suscita el ahínco del escritor por analizar las premisas y fases que conciernen al iter lógico que debe tomar el judicial al momento de realizar la motivación de su decisión, tomando en cuenta las pruebas vertidas en el proceso para verificar las afirmaciones que sobre los hechos realizan las partes en los escritos iniciales demanda y contestación, eventualmente reconvención.

\section{Sistemas de valoración de la prueba}

Antes de entrar en el análisis del proceso de valoración, es menester realizar, aunque carente de toda disquisición, un apunte sobre los sistemas de valoración de la prueba para identificar cuántos son (esto es, su número), y cuál de ellos reguló nuestro legislador nicaragüense en la Ley No. 902. La doctrina procesalista ha debatido si existen tres sistemas de valoración de la prueba - el llamado sistema tasado, el sistema de la sana crítica, y el sistema de libre valoración - o únicamente dos sistema de valoración de la prueba - el sistema tasado y el sistema libre motivado (Lluch, 2014).

Siguiendo a este autor, dos son los sectores doctrinales que riñen los sistemas de valoración de la prueba, uno minoritario, quien afirma que son tres los sistemas de valoración de la prueba (el de la prueba legal, el del íntimo convencimiento y el de la persuasión racional), y otro, el mayoritario, al cual me adhiero, que distingue dos sistemas de valoración (el de la prueba legal y la de libre valoración).

El argumento de este último sector se basa en que la libre valoración es siempre un sistema motivado, siendo el de mayor acierto, el de reconocimiento de dos posibles modelos teóricos de valoración (prueba tasada y prueba libre), en el bien entendido que la libertad en la valoración no equivale a discrecionalidad o arbitrariedad del judicial, y que en el valor legal o tasado, el legislador ha establecido unas determinadas reglas que fijan taxativamente el valor a asignar a cada uno de los medios de prueba (Serra, 2009, p.77). 
La distinción entre uno y otro sistema de valoración la podemos sintetizar siguiendo a Taruffo $(2002,387)$, para quien:

El sistema de prueba legal consiste en la producción de reglas que, predeterminan, de forma general y abstracta, el valor que debe atribuirse a cada prueba; mientras que el sistema de prueba libre presupone la ausencia de aquellas reglas (las que predeterminan el valor de la prueba), e implica que la eficacia de cada prueba para la determinación de los hechos sea establecida caso a caso, siguiendo criterios no predeterminados, discrecionales y flexibles, basados esencialmente en presupuestos de la razón.

Dicho de otra manera, en el sistema de prueba tasada es la ley la que, sin tener en cuenta el convencimiento del juzgador, le señala la forma como ha de valorar las pruebas, imponiendo el criterio legal, y el sistema de libre valoración supone que el juez es libre de valorar los medios de prueba introducidos al proceso, sin que dicha libertad lleve aneja arbitrariedad, pues la legitimidad de la decisión del juzgador radica en la motivación de su decisión.

En este orden de ideas, resulta necesario plantear bajo cuáles de estos dos sistemas de valoración de la prueba se ha regido nuestra legislación en materia civil. Con respecto a la norma procesal anterior, el centenario Código de Procedimiento Civil (Pr), regulaba el sistema de la prueba legal o tasada bajo los alcances del artículo $1395 \mathrm{Pr}$, señalando en sus nueve incisos la prevalencia (orden de prelación), de determinados medios de prueba sobre otros. En palabras del maestro Chiong (2014), uno de mis profesores de derecho procesal, lo que el articulo 1395 Pr. prescribía era el "ranking de las pruebas", haciendo alusión a ese orden de importancia que tenía una prueba con respecto a la otra.

En el actual cuerpo normativo, la Ley No. 902, como regla general en el Libro Segundo; Título I; Capítulo VII, acoge el sistema de libre valoración de la prueba; el artículo 251 establece que:

La valoración de la prueba en el proceso civil, deberá ser motivada de manera clara, precisa y razonada en la sentencia, atendiendo siempre a las reglas de la sana crítica, del conocimiento y criterio humano, así como de acuerdo a las normas que rigen el razonamiento lógico.

No obstante, como toda regla general, este sistema de valoración libre de la prueba presenta su excepción:

1. Para el caso de la prueba documental se prevé una suerte de eficacia privilegiada respecto de determinados extremos. Así, la valoración tasada de los documentos públicos únicamente se circunscribe: a) al hecho, acto o estado de cosas que documenten, y que motivó su otorgamiento; b) lugar y fecha de este; c) a la identidad de los fedatarios y demás personas que intervengan en él. (Art. $273 \mathrm{CPCN}$ y 2374 Código Civil). En estos mismos términos se aplica para los documentos privados que no sean impugnados por la parte a quien le perjudique. (Art. $276 \mathrm{CPCN}$ ). Fuera de estos extremos los documentos se valoraran libremente por el juez con forme a las reglas de la sana critica.

2. En el interrogatorio de partes, el párrafo primero del art. $266 \mathrm{CPCN}$, contiene el carácter tasado al expresar que se consideraran como probados los hechos, objeto del interrogatorio de partes, si se dan los siguientes requisitos: a) si son reconocidos como ciertos; b) si en ellos intervino personalmente la parte; c) si esa fijación como ciertos le es enteramente perjudicial y; d) si no lo contradice el resultado de las demás pruebas (principio de valoración conjunta de las pruebas). La falta de concurrencia de alguno de estos parámetros faculta al juzgador para valorar este medio de prueba conforme a las reglas de la sana critica (libre valoración). 
En suma, la actual ley procesal en materia civil ha optado por el establecimiento de un sistema de valoración libre de la prueba, pues salvo las excepciones planteadas, existe una gran libertad valorativa por el juez conforme a las reglas de la sana crítica.

\section{Premisas de la decisión judicial}

Hasta este punto se ha realizado un esfuerzo para expresar algunas generalidades del tema que se propone desarrollar, haciendo énfasis en los sistemas de valoración de la prueba y cuál de ellos acogió el legislador en la Ley No. 902. Corresponde ahora referirnos al núcleo de este pequeño escrito, en donde primeramente se tratará de ahondar en las premisas, para posteriormente hacer hincapié en las fases de la decisión judicial.

Según plantea Lluch (2014), las pautas que llevan al juez a la comprobación de las afirmaciones que sobre los hechos realizan las partes, descansan sobre una serie de premisas que a modo de presupuesto, en orden cronológico y siguiendo el normal desarrollo del proceso, son: a) la fijación de los hechos controvertidos; b) la admisión de las pruebas; c) la práctica de las pruebas; y d) las conclusiones de los letrados.

\section{La fijación de los hechos controvertidos}

Tras realizarse en debida forma la fase de alegaciones (demanda y contestación), ocurre en el proceso civil, como trámite oral y concentrado, la realización de la audiencia inicial, que una vez concretadas las finalidades de instar a las partes a lograr un arreglo, permitir el saneamiento de los defectos procesales alegados, fijar con precisión la pretensión y la oposición, se presenta la fijación de los términos del debate (hechos controvertidos). (Art. $441 \mathrm{CPCN}$ ).

Esta fijación de los hechos controvertidos en la audiencia inicial del juicio ordinario (art. 456.1 $\mathrm{CPCN}$ ) o en la audiencia única del juicio sumario (art. $506 \mathrm{CPCN}$ ), ofrece una gran ventaja, ya que facilita el juicio de admisión de los medios de prueba. De ahí que, y en palabras de Lluch, "la prueba admisible debe referirse a los hechos controvertidos, de modo que la fijación de éstos opera como presupuesto y antecedente necesario del juicio sobre la admisión de los medios de prueba”. (2014, p. 22).

Por consiguiente, de realizarse una correcta fijación de los hechos controvertidos y una admisión de prueba que contribuya a esclarecerlos (utilidad de los medios de prueba), permitiría "al juez hacerse, ya desde un principio, una idea clara sobre la litis que tiene entre manos, lo que facilitará el dictado de la futura sentencia”. (Lluch \& Picó i Junoy,2006, p.82).

De lo que se trata entonces es de obtener, por un lado, aquellos hechos que resultan admitidos por las partes, los cuales estarían exentos de prueba (artículo 235.1 CPCN), y por otro, los hechos controvertidos que fungirían como presupuesto de la admisión de pruebas.

Nuestro legislador, en cumplimiento del principio omnis definitio in jure periculosa est ${ }^{1}$, no ofrece una definición de lo que se debe entender por hecho controvertido, y con todo acierto es así, pues no es labor del legislador brindar definiciones. Caso contrario sucede en la doctrina donde no faltan quienes, por la solvencia de sus razonamientos, se atreven a expresar que el hecho controvertido es aquel hecho que afirmado por una parte es negado por la otra (Carnelutti, 1982). 
La Ley No. 902 ha prescrito una suerte de carga procesal, tanto para el juez como para las partes, de fijar los hechos controvertidos. De ahí que varios artículos establezcan un nexo vinculante entre los medios de prueba a practicar y el hecho controvertido oportunamente fijado, teniendo en cuenta que aquellos tienen la finalidad de verificar las afirmaciones que sobre estos se realicen.

A modo de ejemplos se pueden precisar el artículo $13 \mathrm{CPCN}$, que consagra el principio de "Aportación de parte", párrafo segundo "las pruebas que deban practicarse para la acreditación de los hechos controvertidos, han de ser aportadas por las partes en el momento procesal dispuesto por este Código"; artículo 292 CPCN "las partes podrán proponer cuantos testigos estimen convenientes por cada hecho controvertido". En cuanto a los requisitos legales de admisión de las pruebas, el artículo 236.4 CPCN expone que "serán pruebas útiles aquellas que razonablemente contribuyan a esclarecer los hechos controvertidos"; relativo a las finalidad de la audiencia inicial, resultando la disposición que reafirma dicha carga procesal, el artículo 441 CPCN "la audiencia inicial servirá para (...) fijar con precisión la pretensión y la oposición, así como los términos de su debate".

\section{La admisión de las pruebas}

La prueba resulta ser una parte medular del proceso y su admisibilidad está sometida a unos parámetros o criterios jurídicos, y a un criterio lógico como es la relevancia de la prueba.

Parafraseando a Lluch (2014), la relevancia de los medios de prueba se refiere a la incidencia o necesidad de la prueba en los términos de la decisión judicial, siendo este un juicio hipotético, pues anticipa la trascendencia del medio de prueba propuesto con los hechos objetos de prueba, en donde se excluyen las pruebas que no aportan elementos de conocimiento sobre los hechos controvertidos y se integran aquellas pruebas con trascendencia para la verificación, positiva o negativa, de un hecho controvertido.

En cuanto a la admisibilidad, nuestra ley procesal hace referencia a requisitos de licitud, pertinencia, utilidad y necesariedad de los medios de prueba (art. $236 \mathrm{CPCN}$ ), de modo que el judicial debe prestar puntual atención a estas exigencias al momento de emitir su resolución sobre la admisión o inadmisión de las prueba, ya que debe pronunciarse de manera individualizada (sobre cada medio de prueba propuesto) y motivadamente (expresando las razones que permiten la inclusión o exclusión de las pruebas).

Además de los requisitos apuntados, operan como presupuestos de este juicio de admisión la previa proposición de los medios de prueba (normalmente en los escritos iniciales, art. 420.8 CPCN) y la fijación de los hechos controvertidos (art. $441 \mathrm{CPCN}$ ). Por un lado, la delimitación de los hechos controvertidos permite fijar el tema de prueba, y por otro, el judicial debe prestar atención a la formalidad y temporalidad en el modo de proposición de la prueba, pues la ley procesal exige con gran rigor acatar los momentos procesales oportunos para proponerla; de lo contrario, su inobservancia trae como consecuencia que la prueba sea tenida, aunque erróneamente, como ilícita (art. 237.2) CPCN. 
Resulta interesante hacer referencia a este requisito de admisión de la prueba, dada la especial confusión que se ha introducido en el artículo $237 \mathrm{CPCN}$, concerniente a la distinción entre prueba ilegal y prueba ilícita. Es unánime la doctrina al entender como prueba ilícita aquella que en su obtención o práctica vulnere los derechos fundamentales, no debiendo confundirse con otros, como la prueba ilegal, que es aquella que se admite sin observancia de los requisitos concernientes a las formalidades legales de tiempo y forma.

En este orden, nuestra ley procesal equipara erróneamente la prueba ilícita con las acepciones antes enunciadas, como si se tratara de un término de aplicación indistinto, obviando que estos supuestos están totalmente diferenciados en otras legislaciones, a nivel doctrinal y jurisprudencial.

Bajo el alcance de los artículos 236 y 239 CPCN, el juzgador debe censurar ab initio la proposición de pruebas en las que se vulneren derechos fundamentales y garantías procesales (prueba ilícita), así como aquellas que no cumplan con los requisitos referidos a la proposición y admisión (prueba ilegal), tomando en cuenta los momentos procesales establecidos en el artículo 238 CPCN y la alegación que sobre la ilicitud hiciere alguna de las partes.

Comprobada la ilicitud de una prueba, esta carece de toda eficacia probatoria según las voces del artículo 237.4 CPCN, o como mejor lo expresa el artículo 16 de la Ley Orgánica del Poder Judicial (LOPJ): "no surten efecto alguno en el proceso las pruebas substraídas ilegalmente $u$ obtenidas violentando, directa o indirectamente, los derechos y garantías constitucionales”, y la vulneración de esta prohibición es susceptible de recurrirse alegando la infracción de las normas que rigen los actos y garantías procesales susceptibles de causar indefensión.

Basta entonces apuntar que el juzgador se encuentra ante una enorme labor al realizar el juicio de admisión de la prueba, labor que debe realizar con cautela, en el bien entendido que ese juicio de admisión constituye el salvoconducto para la práctica de los medios de prueba.

\section{La práctica de las pruebas}

Salvo ciertas excepciones, una vez que las pruebas han sido propuestas y admitidas en debida forma, deben practicarse, pues la ausencia de práctica de una prueba previamente admitida resulta ser una inadmisión no motivada.

En este momento del proceso, el judicial debe agudizar sus sentidos para tener en cuenta las particularidades que cada medio de prueba presenta al momento de ser practicado, salvo el caso de la documental que no necesita una fase de práctica propiamente dicha. El trámite de práctica de la prueba está previsto para que se desarrolle en audiencia oral y pública, de forma concentrada y con plena vigencia del principio de inmediación (arts. 460 y $461 \mathrm{CPCN}$ ).

La concentración o unidad de acto "es uno de los principios inspiradores del procedimiento probatorio" (Lluch; 2012: 233). Por consiguiente, resulta prioritario que tanto el juez como las partes tengan en cuenta cuáles son sus facultades durante el desarrollo de esta audiencia. Respecto al juez como director del proceso, la ley procesal otorga ciertas facultades de intervención durante la práctica de las pruebas, que no necesariamente son las de dirección formal, tal como sucede en el interrogatorio de partes y peritos (art. 258.3 y 323 parte final CPCN, respectivamente), bajo el supuesto que el juez interviene, en el primero, con la finalidad de obtener aclaraciones y adiciones sobre los hechos declarados, y en el segundo, para requerir explicaciones que ayuden a comprender y valorar mejor el dictamen realizado. 
El juez, en esta etapa de práctica de las pruebas, se encuentra en contacto directo con las fuentes de prueba (la persona llamada a declarar, a rendir testimonio y otros), situación que le permite que pueda apreciar con mayor alcance la credibilidad de las declaraciones. Pero no debe abusar de esas facultades materiales que le ha conferido el legislador, ya que el uso arbitrario y deliberado puede dar lugar a que las partes utilicen los mecanismos necesarios para garantizar en el juez la debida imparcialidad que es la "fuente purificante de la justicia" (Calamandrei, 2009, p.11).

En cuanto a las partes, deben ser los principales interesados en que se practiquen los medios de pruebas propuestos y admitidos, en el bien entendido que de su práctica depende la verificación de los hechos fijados como controvertidos, de tal suerte que sin la práctica del acervo probatorio no existe proceso de valoración de la prueba.

\section{Las conclusiones de los letrados}

Concluida la práctica de las pruebas y antes de que finalice la audiencia probatoria, se concede a las partes un turno para que procedan a exponer sus alegatos finales. Para los letrados este es el momento oportuno en el que de forma oral, clara y ordenada, relatan cuáles hechos resultan probados y en virtud de qué medio de prueba, así como rebatir las pretensiones de la parte contraria, sin obviar que la base de sus alegatos son los hechos controvertidos y el acervo de pruebas practicadas.

En cuanto al juez, es un trámite trascendental "porque tiene la oportunidad de escuchar la versión de cada letrado con respecto de los hechos controvertidos y de los medios de prueba que acreditan o desacreditan los mismos, y todo ello con anterioridad al momento de dictar sentencia" (Lluch, 2014, p. 35).

No se trata de dar rienda suelta a los torrentes de la elocuencia ante el juzgador. El letrado debe evitar convertir este trámite en un resumen de los escritos de alegaciones. ¡No vaya a ser censurado por la prolijidad!

La ley procesal es clara y establece que en las conclusiones se deben fijar, concretar y adecuar tanto los hechos como las peticiones, con base en el resultado de la práctica de las pruebas. No existe un único modelo de efectuar los alegatos; no obstante, siguiendo las recomendaciones de Lluch (2014), en aquellos supuestos en los que en la audiencia inicial se hayan fijado los hechos controvertidos, puede resultar útil tomar los mismos como punto de partida e ir desgranando los medios de prueba que acrediten la versión de los hechos que interesan a nuestras pretensiones y desacreditan la parte contraria. Para que este ejercicio resulte completo, según lo señalado en el artículo 201.2 $\mathrm{CPCN}^{3}$, deberá ser realizado de manera separada respecto de cada medio de prueba y a la vez de manera conjunta.

\section{Fases de la decisión judicial}

Al igual que las premisas de la decisión judicial, Lluch (2014) plantea que para llegar a la sentencia el juez pasa, idealmente, por un proceso que consta de tres fases o momentos: a) la interpretación de los resultados probatorios; b) la valoración de los medios de prueba; y c) la motivación (del juicio de hecho y de derecho). El autor advierte que estas tres fases tiene lugar en la mente del juez y que se exteriorizan en la resolución judicial por medio de la motivación. 
La interpretación de los resultados probatorios es una fase preliminar que el juez realiza y que no debe confundirse con la fase de valoración. Se distinguen una de la otra tomando en cuenta que en una primera fase el juez realiza una labor operativa de determinación de los resultados que arrojan los medios de prueba (fase de interpretación) y en otra, la atribución del correcto valor de los medios de prueba (fase de valoración).

Se afirma que interpretar una prueba significa fijar su resultado, esto es, qué ha dicho el testigo, cuáles son las máximas de experiencia que aporta el perito o cuál es el contenido de un documento; mientras que valorar una prueba significa otorgar la credibilidad que merece atendiendo al sistema de valoración, ya sea este tasado o libre. (Luch, 2012, p.60). De esta manera, la interpretación es la punta de lanza con que el juez inicia el proceso de valoración.

\section{La valoración de los medios de prueba}

La valoración de la prueba es una de las labores jurisdiccionales que ha recobrado interés en nuestro sistema procesal civil, debido al cambio de paradigma que ha introducido la Ley No. 902, en la forma de valorar los resultados probatorios. En líneas arriba apuntábamos que la ley procesal anterior prescribía el valor que a cada prueba debía otorgarse, quedando el juez sustraído de plasmar su propia valoración.

Salvo las excepciones descritas, actualmente el juez consta de plenas facultades para valorar libremente las pruebas practicadas, conforme a la reglas de la sana crítica, del conocimiento y criterio humano, así como de acuerdo con las reglas que rigen el razonamiento lógico (art. 251.1 CPCN). No obstante, esta libertad se ve limitada por el deber de motivación como requisito interno de la sentencia (art. 201.1 CPCN)4.

Aunque sugestiva, pero muy esclarecedora, resulta la definición de sana critica planteada por Lluch (2014, p.68), quien citando a Guasp expresa que "son los criterios normativos (reglas, pero no jurídicas), que sirven al hombre normal, en una actitud prudente y objetiva (sana), para emitir juicios de valor (estimar, apreciar: acerca de una cierta realidad)"; es decir, normas de criterio fundadas en la experiencia y la lógica humana.

En referencia a la sana crítica, Lluch plantea que está compuesta de "las reglas no jurídicas derivadas de la lógica, la experiencia y la ciencia que sirven para fundar una valoración razonada de la prueba y permiten su control por otro órgano superior". (2014, p.69). Partiendo de lo planteado, el juzgador deberá utilizar estas reglas en la valoración del resultado probatorio, aplicándolas para los medios de prueba que se valoran libremente, y poniéndolas en relación con la valoración tasada de otros.

En la valoración de los medios de prueba el juez se encuentra ante una doble labor. En un primer momento se le exige valorar individualmente cada medio de prueba, unos conforme a la sana crítica, otros otorgándole el valor tasado preestablecido. En un segundo instante, se encuentra obligado a valorar la prueba de manera conjunta poniendo en relación unos medios de pruebas con otros a fin de otorgar a cada uno, en consideración a los restantes, el valor o grado de eficacia que le corresponde.

Esta operación le permitirá al juez conocer qué medios de prueba se complementan en la verificación de uno o varios hechos controvertidos (concurrencia de los medios de prueba), y cuáles entran en conflicto (colisión de medios de prueba). 
Sin embargo, en tales casos y para que la aplicación de la apreciación conjunta se realice correctamente es inexorable que el juez "indique qué medios de prueba conforman el conjunto, cómo apuntan todos a la misma dirección acreditativa, y en qué forma se complementan los unos con los otros" (Luch, 2014, p.121).

\section{La motivación}

El derecho constitucional a obtener una sentencia motivada (art. $34.8 \mathrm{Cn}$ ) y recogido en el artículo 201.1 CPCN, incide tanto en el juicio de hecho como en el juicio de derecho. Y es que el razonamiento del judicial debe comulgar con un razonamiento argumentativo, es decir, tendente a justificar su decisión; con opinión crítica y jurídicamente valorativa sobre los componentes facticos y jurídicos presentados por las partes (Nivea, 2010).

De acuerdo con Lluch (2014, p.146), la motivación:

...es la exteriorización de las razones que llevan al juez a tener por acreditado unos determinados hechos a partir de unos medios de prueba y de las razones para la aplicación e interpretación del derecho de una determinada manera en la sentencia.

En este orden, la motivación de la sentencia debe expresar qué hechos han quedado probados y en virtud de qué medio de prueba; asimismo, debe indicar la norma jurídica aplicable al caso concreto, pues como se ha sostenido a nivel doctrinal: "la legitimidad del juez radica en la motivación de la resolución judicial”. (Luch, 2012, p.511). Por ello, esta fase es una de las tareas más arduas en la labor de juzgar, ya que configura un deber del judicial y, a su vez, un derecho de las partes a obtener decisiones judiciales motivadas y con posibilidad de ser controladas por los justiciables, los tribunales superiores y hasta por la sociedad.

Tanto la fase de interpretación como de valoración de los resultados probatorios se complementan con la motivación; las dos primeras permanecen intangibles en la mente del juez, y aunque la fase de motivación también inicia en el arcano del juez, se plasma en la sentencia, pasando a ser la expresión externa y formal del proceso de la decisión judicial

Para terminar este apartado quisiera reproducir las palabras de Calamandrei (2009, p.123), quien en el abordaje de la motivación de la sentencia ha dicho que:

La motivación de las sentencias es, verdaderamente, una garantía grande de justicia, cuando mediante ella se consigue reproducir exactamente como en un croquis topográfico, el itinerario lógico que el juez ha recorrido para llegar a su conclusión; en tal caso, si la conclusión es equivocada, se puede fácilmente determinar, a través de los fundamentos, en qué momento de su camino, el juez ha perdido la orientación.

\section{Algunas consideraciones finales}

Se torna oportuno apreciar la importancia que tiene tanto para el judicial como para las partes conocer el iter que permite llegar a una conclusión dentro del proceso (sentencia), ya que siendo la sentencia el acto jurisdiccional en que el juzgador emite su juicio sobre la conformidad o disconformidad de la pretensión, deben tomarse las mejores precauciones en aras de garantizar que la decisión judicial tomada se apegue a derecho.

Es un hecho que el sistema de valoración de la prueba que rige nuestro actual proceso civil es el de libre valoración, pues salvo las excepciones apuntadas, las pruebas se valorarán libremente conforme las reglas de la sana crítica, del conocimiento y criterio humano, y de acuerdo con las normas que rigen el razonamiento lógico 
En cuanto a las premisas de la decisión judicial basta recordar que ellas se producen a lo largo del proceso y en orden cronológico (la fijación de los hechos controvertidos, la admisión de las pruebas, la práctica de las pruebas y las conclusiones de los letrados). Por lo tanto, las partes como el juez son garantes para que se lleven a cabo con apego a las reglas de procedimiento establecidas.

Respecto a las fases que recorre el judicial para poder plasmar su decisión en la sentencia, se debe recordar que todas se ventilan en la mente de quien realiza esta labor; no obstante, cuando el juez plasma su decisión se ve en la obligación de motivarla, expresando los razonamientos fácticos y jurídicos que conducen a la apreciación y valoración de la prueba, así como a la aplicación e interpretación del derecho.

\section{Referencias bibliográficas}

- Asamblea Nacional. (1906). Código de Procedimiento Civil. Managua: Jurídica.

- Asamblea Nacional (1987). Constitución Política de Nicaragua. Managua: Jurídica.

- Asamblea Nacional (1998). Ley Orgánica del Poder Judicial. Managua: Jurídica.

- Asamblea Nacional (2015). Código Procesal Civil. Managua: Juridica.

- Calamandrei, P. (2009). Elogio de los jueces escrito por un abogado. (S. Sentis, \& I. Medina, Trads.) Madrid: Góngora.

- Chiong, F. (2014). El proceso ordinario. Managua, Nicaragua.

- Cuadra, J. (2004). Anotaciones al Código Civil de Nicaragua (Primera ed.). Managua, Nicaragua: HISPAMER.

- $\quad$ Lluch, X. (2012). Derecho Probatorio. Barcelona: BOSCH.

- $\quad$ Lluch, X. (2014). La valoración de la prueba en el proceso civil. Madrid: LA LEY.

- $\quad$ Lluch, X., \& Picó i Junoy, J. (2006). Aspectos prácticos de la prueba civil. Barcelona: Bosch.

- $\quad$ Nivea, J. (2010). La Valoración de la Prueba. Madrid: Marcial Pons.

- Serra, M. (2009). Estudios de Derecho Probatorio. Lima: Communitas.

- $\quad$ Taruffo, M. (2002). La prueba de los hechos (F. Beltran, Trad.) Madrid: Trotta. 


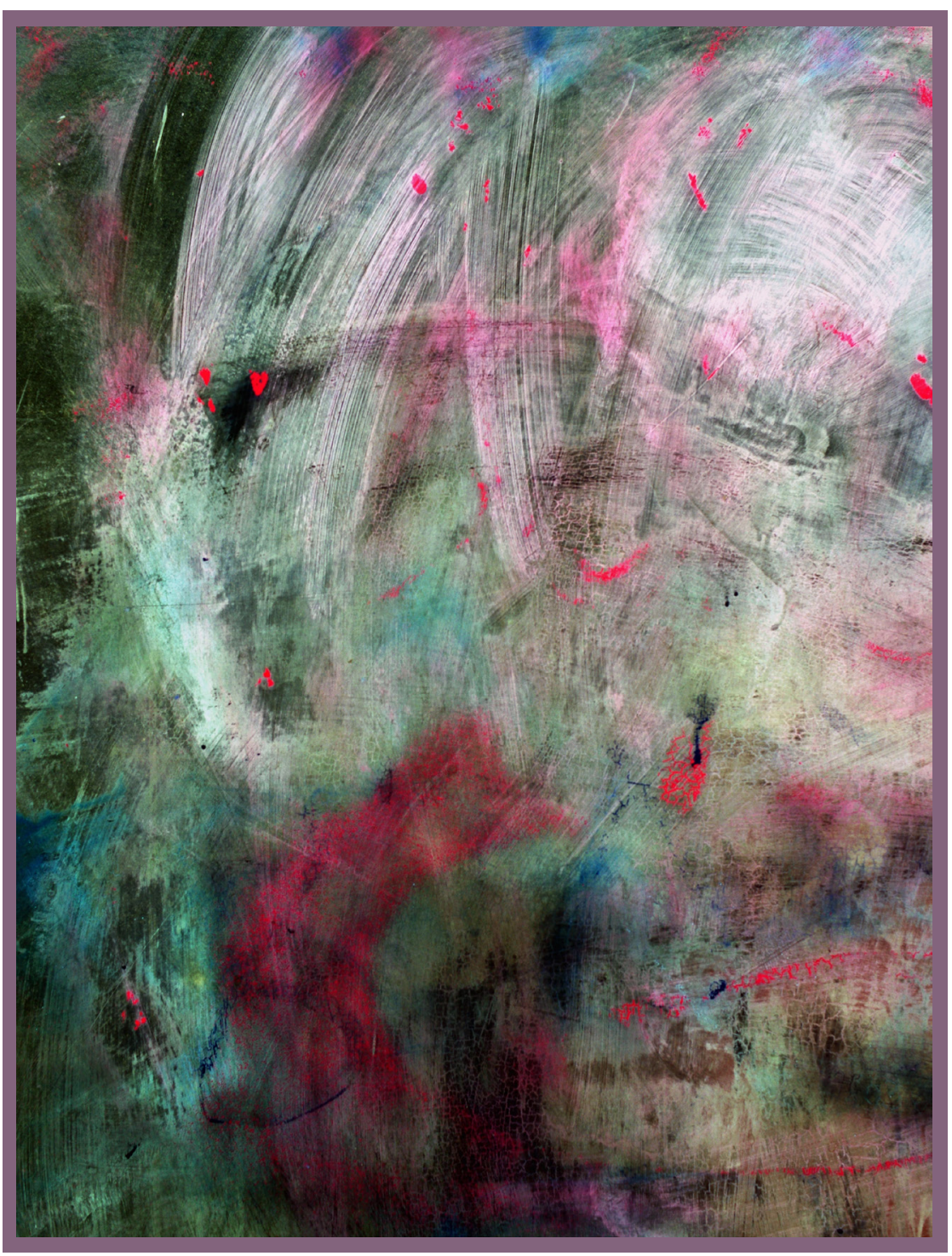

Arte de Nate Bell

Everto Álvarez Jiménez Docente-Investigador Departamento de Derecho Fac. de Humanidades y Ciencias Jurídicas UNAN-Managua ORCID. 0000-0002-0332-8170 e.alvarezjimenez@hotmail.com 